\title{
LOW-LEVEL LASER THERAPY AFTER CARPAL TUNNEL RELEASE
}

Marcelo de Pinho Teixeira Alves ${ }^{1}$, Gabriel Costa Serrão de Araújo ${ }^{2}$

\section{ABSTRACT}

Objective: Evaluate the post-operative treatment of CTS, using the LLLT. Method: We prospectively evaluated 58 patients with CTS, randomly divided into two groups: treatment with LLLT (Group 1) and placebo (Group 2). A $830 \mathrm{~nm}$ gallium-aluminum-arsenic laser was used, with a power of 30 $\mathrm{mW}$. Results: There was female predominance in both groups. The mean age of the patients in Group 1 was 44.3 years and in Group 2, 51.9 years. The average duration of disease progression was around two years in both groups. The average time elapsed since discharge from treatment was 3.6 months in both groups, and fewer patients had postoperative complaints in Group 1 than in Group 2. At the end of the treatment, in
Group 1, 29.41\% of the patients presented electromyographic abnormalities, while in Group 2, 63.64\% of the patients had abnormalities, after six months. Conclusion: This was an initial study on adjuvant therapy using postoperative LLLT on CTS. The method presented was sufficient for postoperative evaluation of the patients in this study. Patients undergoing LLLT after surgery for CTS were benefited and had better functional outcomes than shown by the control group. The technique was effective and did not have any adverse effects on the patients studied.

Keywords - Carpal Tunnel Syndrome; Median Neuropathy; Laser Therapy, Low-Level; Postoperative Period

\section{INTRODUCTION}

Carpal tunnel syndrome (CTS) is a disease characterized by compression of the median nerve when this passes below the flexor retinaculum of the wrist, and is associated with functional alterations of the nerve ${ }^{(1)}$.

Individuals with the disease in an advanced stage present the median nerve extended in the region proximal to the carpal tunnel and stenosed inside the tunnel, with a bluish coloration, typical of chronic ischemia. Atrophy of the thenar region may be present in these cases ${ }^{(1)}$.

Patients usually complain about progressive loss of strength in the hand, especially in thumb opponency, paresthesia in median nerve sensory distribution and pain in the palmar region, with characteristic nighttime pain that causes awakening from sleep. Both hands can be affected, yet the symptoms are generally worse in the dominant hand. Middle-aged women constitute the majority of patients ${ }^{(1)}$.

The clinical diagnosis is based on the history of the disease and physical examination, especially Tinel's sign and the Phalen and Durkan tests. Tinel's sign is verified with digital percussion along the course of the median nerve through the carpal tunnel, which causes an electric shock sensation in the nerve distribution territory. Phalen's test consists of flexion of the wrists with the elbows flexed at $90^{\circ}$ and shoulders in abduction in the scapular plane of $90^{\circ}$, for approximately one minute, causing exacerbation of the sensory alterations perceived by the patient ${ }^{(1)}$. Compression of the wrist caused by the examiner induces pain and also exacerbates the symptoms, and is called the Durkan test; it is the most sensitive of clinical tests for the disease ${ }^{(2)}$.

Factors associated with the disease include obe-

\footnotetext{
1 - Full Member of the Brazilian Association of Hand Surgery; Studying towards Master's Degree in Medical Sciences from Universidade Federal Fluminense; Physician of the Hand Surgery Outpatient Clinic of Hospital Universitário Antônio Pedro - Universidade Federal Fluminense - Niterói, RJ, Brazil.

2 - Third-year Orthopedics and Traumatology Resident of Hospital Universitário Antônio Pedro - Universidade Federal Fluminense - Niterói, RJ, Brazil.

Study conducted at the Orthopedics and Traumatology Clinic of Hospital Universitário Antonio Pedro of the Universidade Federal Fluminense - UFF.

Mailing address: Serviço de Ortopedia do HUAP/UFF, Av. Marques de Paraná, 303 - 24033-090 - Niterói, RJ. Email: marceloptalves@hotmail.com

Study received for publication: 7/7/2010, accepted for publication: 7/4/2011.
}

The authors declare that there was no conflict of interest in conducting this work

This article is available online in Portuguese and English at the websites: www.rbo.org.br and www.scielo.br/rbort 
sity, hypothyroidism, diabetes mellitus, pregnancy, kidney disease, inflammatory arthritis, acromegaly, mucopolysaccharidosis, advanced age, smoking and extreme, repetitive flexion of the wrist ${ }^{(2)}$. It is necessary to investigate other diseases that cause similar symptoms, such as: cervical radiculopathy, lesions of the brachial plexus, thoracic outlet syndrome, neoplasias of the pulmonary apex, pronator syndrome, cubital and ulnar tunnel syndromes and secondary peripheral neuropathies.

Electrophysiological evaluations of the median nerve, such as nerve conduction velocity and electromyography, are used to confirm the clinical diagnosis. The decrease in amplitude of the action potential, the increase of distal latency and the reduction of nerve conduction velocity are findings considered abnormal. Distal motor and sensory latencies above $4.2 \mathrm{~ms}$ and $3.5 \mathrm{~ms}$, respectively, are generally considered parameters of abnormality ${ }^{(3)}$. There are recent studies suggesting the complementary use of wrist ultrasonography, with measurement of the cross-sectional area of the median nerve, as an aid in the diagnosis and supervision of CTS treatment ${ }^{(4)}$. Some authors relate the disease's diagnosis and its severity to the results obtained after evaluation of the self-administered Boston questionnaire $^{(5)}$.

Therapeutic methods range from observation of disease evolution alone, wrist immobilization and local injection of corticosteroids, to surgery ${ }^{(6)}$. Conservative treatments have satisfactory results in most cases, when the symptoms have been present for less than a year ${ }^{(2)}$. Surgery is reserved for cases that are refractory to conservative treatment and for those in advanced stages of the condition, with atrophy of the thenar region or electrophysiological evidence of denervation. The complications of surgery are well documented in literature and include the persistence of symptoms, which is closely related to the surgeon's experience for complete release of the carpal tunnel ${ }^{(2)}$. Common concerns in the postoperative period are pain, relief of nerve compression symptoms, sensitivity of the scar and time taken to return to work $^{(7)}$.

As an alternative to the conservative treatments described for CTS, many studies have investigated the results of low-level laser therapy (LLLT) in the relief of symptoms and in the functional recovery of the median nerve. In patients with slight and moderate CTS, Chang verified that laser therapy was effective in the relief of pain and symptoms, and improved the functional ability of the fingers and strength of the hand, not observing side effects ${ }^{(8)}$. Yagci et al $l^{(9)}$ compared the treatment using immobilization of the wrist and immobilization associated with sessions of lowlevel laser therapy in patients with CTS, concluding that the electrophysiological parameters were better after the associated treatment. A randomized, doubleblind, placebo-controlled Canadian trial, conducted with 16 patients with CTS, demonstrated a placebo effect of LLLT, and the inefficacy of the therapeutic method $^{(10)}$; Bakhtiary and Rashidy-Pour concluded that ultrasound is superior to laser therapy in the conservative treatment of $\mathrm{CTS}^{(11)}$. In the comparison between LLLT and surgical release of the carpal tunnel for the treatment of CTS, it was concluded that laser therapy is effective in initial cases with slight to moderate symptoms, when pain is the main symptom present, while surgery is reserved for advanced and chronic cases of the disease. These authors also suggest using LLLT to relieve residual pain after surgical treatment $\mathrm{t}^{(12)}$.

It is believed that low-level laser radiation stimulates cell proliferation, by a photochemical reaction that changes the permeability of the cell membrane. Laser therapy has been used to stimulate the healing of wounds, for neuronal regeneration and in pain control.

Rochkind et $a l^{(13)}$ demonstrated the presence of stimulation of cell growth of rat embryo neurons that received laser therapy radiation in comparison to a control group of non-radiated rats. Gigo-Benato et $a l^{(14)}$ and Rochkind et $a l^{(15)}$ published an extensive bibliographic review of experimental basic studies that demonstrate the stimulation of laser therapy in neuronal growth and in the functional recovery of injured peripheral nerves. A controlled experiment on rats assessed the functional recovery of the ischiatic nerve and the histology of the nerve after three weeks of LLLT for the treatment of surgical crushing of the nerves, concluding that the laser effectively accelerated neuronal regeneration ${ }^{(16)}$.

This study aims to compare the postoperative results of the patients treated with low-level laser therapy with those of the patients treated with placebo laser, in relation to the parameters of pain, persistence of symptoms, return to work or to daily activities and neurophysiological recovery, observed by electroneuromyography. 


\section{CASUISTRY AND METHOD}

The study was composed of 58 patients with carpal tunnel syndrome treated at the Hand Surgery Outpatient Clinic, assessed between May 2009 and January 2011. The patients confirmed their agreement to participate in the study by signing an informed consent form.

The eligibility criteria of this study included patients with a clinical and electroneuromyographic diagnosis of carpal tunnel syndrome, with normal laboratory tests (leukogram, erythrogram, coagulogram, glucose, urea, creatinine, sodium, potassium), and wrist radiographs without osteoarticular lesions. Individuals already submitted to surgical procedures involving the wrist, those who received infiltration at the site, pregnant or breastfeeding women, those using an experimental drug, patients with active infection, or myocardial infarct less than six months earlier or other diseases without adequate clinical control were excluded from the study.

The surgical technique was the same for all the patients from the study, with the classic, longitudinal access route, anterior to the flexor retinaculum, with release of the flexor retinaculum of the wrist, without the performance of median nerve microneurolysis in any patient.

The patients were randomly and sequentially divided into two groups: group 1 - low-level laser therapy (LLLT); group 2 - placebo laser therapy (PLT). The treatment was performed in 10 daily, consecutive sessions, with an interval of two days (weekend), using a total of three Joules, at three points of the carpal tunnel (in the topography of the pisiform bone, in the middle of the carpal tunnel and at the distal limit of the carpal tunnel). Neither group of patients knew the identity of the members of the placebo group or treatment group.

The equipment used was the aluminum gallium arsenide Ibramed ${ }^{\mathbb{B}}$ laser pen, with a wavelength of $830 \mathrm{~nm}$, and power of $30 \mathrm{~mW}$.

Both groups were assessed regularly by the surgeon after the procedure, in visits two weeks after surgery, and in the first, second, third and sixth postoperative months, or until the patients were asymptomatic and capable of returning to work or to their activities of daily living. During the visits, they were evaluated in terms of symptoms of palmar pain, pillar pain, paresthesia, nighttime pain, pain or discomfort at the site of the scar and Tinel>s test, as well as time taken to return to activities of daily living or to work.
Electroneuromyography was performed in the sixth postoperative month, or when the patient was asymptomatic (if this occurred earlier).

The univariate analysis was conducted using Fisher>s exact test to indicate the statistical difference between the groups.

\section{RESULTS}

The patients from group 1 totaled 29. They were all treated surgically and submitted to low-level laser therapy in the wrist during the postoperative period; of these, eight were male and 21 female, with ages ranging between 25 and 80 years (mean age 44.3 years), with 17 right wrists and 12 left; the disease evolution time ranged between six months and 10 years (mean time 1.97 years). Group 2 was formed by 29 patients, four of whom were male and 25 female, with ages between 24 and 89 years (mean age 51.9 years); 19 right wrists and 10 left; the disease evolution time ranged between six months and 10 years (mean time of two years and two months).

The patients were monitored by the surgeon after the procedure until the symptom complaints ceased and the patients were discharged from the treatment program. Thus in both groups the mean time to discharge was 3.6 months, whereas in group 1 it ranged from one to six months to discharge, and in group 2 from one to eight months.

The electroneuromyographic examinations were performed before surgery and six months after surgery, except in cases in which the patient had been discharged from the treatment program before the six months. In group 1, the examination showed abnormalities in $100 \%$ of the patients at the beginning of the treatment and in $29.41 \%$ at the end. In group 2, we had $92.60 \%$ of the patients with neurofunctional alterations at the beginning of the treatment and $63.64 \%$ at the end of the study.

The evaluation of the patients performed at one, two, three and six months considered the complaints of symptoms and the clinical signs of the disease. The results are demonstrated in Table 1, which lists the number of patients and the clinical findings over time. Figure 1 records the total number of patients from both groups with clinical alterations in each evaluation. Figures 2 and 3 individualize the groups and the postoperative complaints.

No patient abandoned the study, or declared themselves dissatisfied with the treatment. They all re- 
turned to their daily activities and were asymptomatic upon medical discharge.

No complications were observed in relation to the surgical procedure, nor did any of the patients from the study groups require further surgery.

Table 1 - Postoperative clinical evaluation.

\begin{tabular}{|c|c|c|c|c|c|c|}
\hline $\begin{array}{c}\text { First } \\
\text { month }\end{array}$ & & & & & & \\
\hline & $\begin{array}{l}\text { Painful } \\
\text { scar }\end{array}$ & $\begin{array}{l}\text { Pillar } \\
\text { pain }\end{array}$ & Numbness & $\underset{\text { pain }}{\text { Nighttime }}$ & $\begin{array}{c}\text { Palmar } \\
\text { pain }\end{array}$ & $\begin{array}{c}\text { Clinical } \\
\text { signs }\end{array}$ \\
\hline $\begin{array}{c}\text { Group 1- } \\
\text { number of } \\
\text { patients }\end{array}$ & 9 & 8 & 3 & 0 & 8 & 3 \\
\hline $\begin{array}{c}\text { Group } 2- \\
\text { number of } \\
\text { patients }\end{array}$ & 16 & 6 & 8 & 0 & 11 & 1 \\
\hline \multicolumn{7}{|l|}{$\begin{array}{l}\text { Second } \\
\text { month }\end{array}$} \\
\hline & $\begin{array}{l}\text { Painful } \\
\text { scar }\end{array}$ & $\begin{array}{l}\text { Pillar } \\
\text { pain }\end{array}$ & Numbness & $\underset{\text { pain }}{\text { Nighttime }}$ & $\begin{array}{c}\text { Palmar } \\
\text { pain }\end{array}$ & $\begin{array}{l}\text { Clinical } \\
\text { signs }\end{array}$ \\
\hline $\begin{array}{c}\text { Group } 1- \\
\text { number of } \\
\text { patients }\end{array}$ & 3 & 4 & 0 & 0 & 1 & 0 \\
\hline $\begin{array}{c}\text { Group } 2- \\
\text { number of } \\
\text { patients }\end{array}$ & 6 & 7 & 6 & 0 & 6 & 3 \\
\hline \multicolumn{7}{|l|}{$\begin{array}{c}\text { Third } \\
\text { month }\end{array}$} \\
\hline & \begin{tabular}{|c|}
$\begin{array}{c}\text { Painful } \\
\text { scar }\end{array}$ \\
\end{tabular} & $\begin{array}{l}\text { Pillar } \\
\text { pain }\end{array}$ & Numbness & $\begin{array}{c}\text { Nighttime } \\
\text { pain }\end{array}$ & $\begin{array}{c}\text { Palmar } \\
\text { pain }\end{array}$ & \begin{tabular}{|c|} 
Clinical \\
signs
\end{tabular} \\
\hline $\begin{array}{c}\text { Group } 1- \\
\text { number of } \\
\text { patients }\end{array}$ & 1 & 4 & 0 & 0 & 0 & 0 \\
\hline $\begin{array}{c}\text { Group } 2- \\
\text { number of } \\
\text { patients }\end{array}$ & 3 & 6 & 3 & 0 & 1 & 0 \\
\hline \multicolumn{7}{|l|}{$\begin{array}{l}\text { Sixth } \\
\text { month }\end{array}$} \\
\hline & \begin{tabular}{|c} 
Painful \\
scar
\end{tabular} & $\begin{array}{l}\text { Pillar } \\
\text { pain }\end{array}$ & Numbness & $\underset{\text { pain }}{\text { Nighttime }}$ & \begin{tabular}{|c} 
Palmar \\
pain
\end{tabular} & \begin{tabular}{|c} 
Clinical \\
signs
\end{tabular} \\
\hline $\begin{array}{c}\text { Group } 1- \\
\text { number of } \\
\text { patients }\end{array}$ & 0 & 0 & 0 & 0 & 1 & 0 \\
\hline $\begin{array}{c}\text { Group } 2- \\
\text { number of } \\
\text { patients }\end{array}$ & 1 & 1 & 2 & 0 & 1 & 0 \\
\hline
\end{tabular}

Source: SOT/HUAP

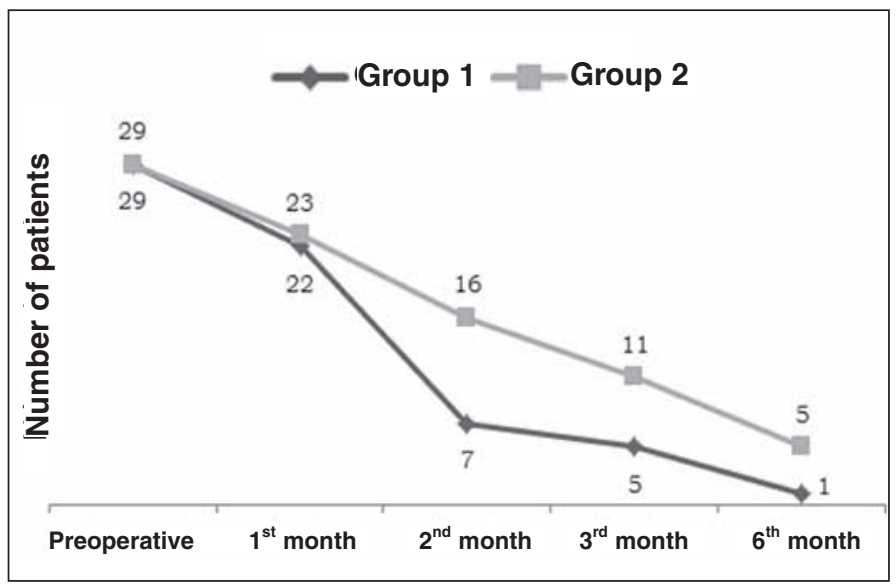

Figure 1 - Total number of patients with complaints, from both groups.

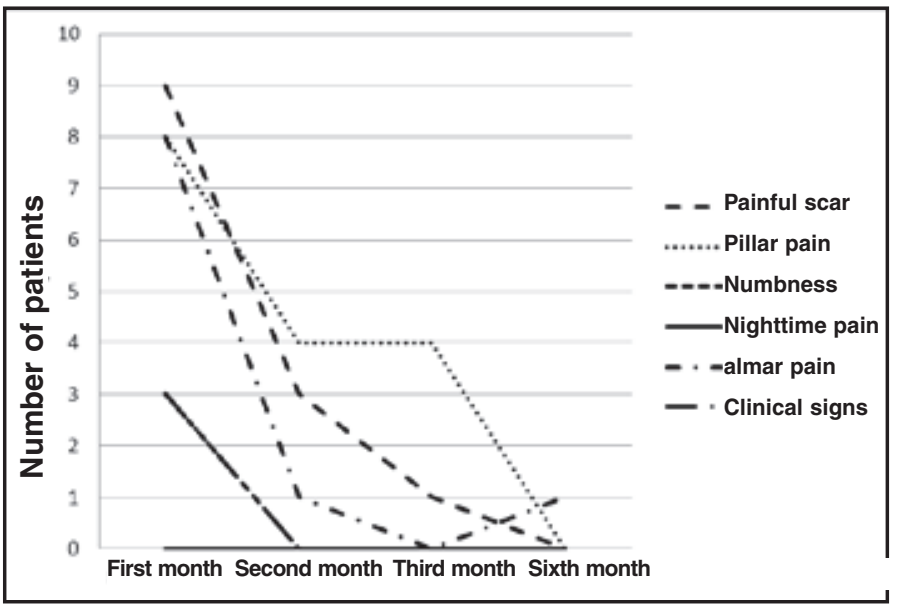

Figure 2 - Evolution of complaints of group 1.

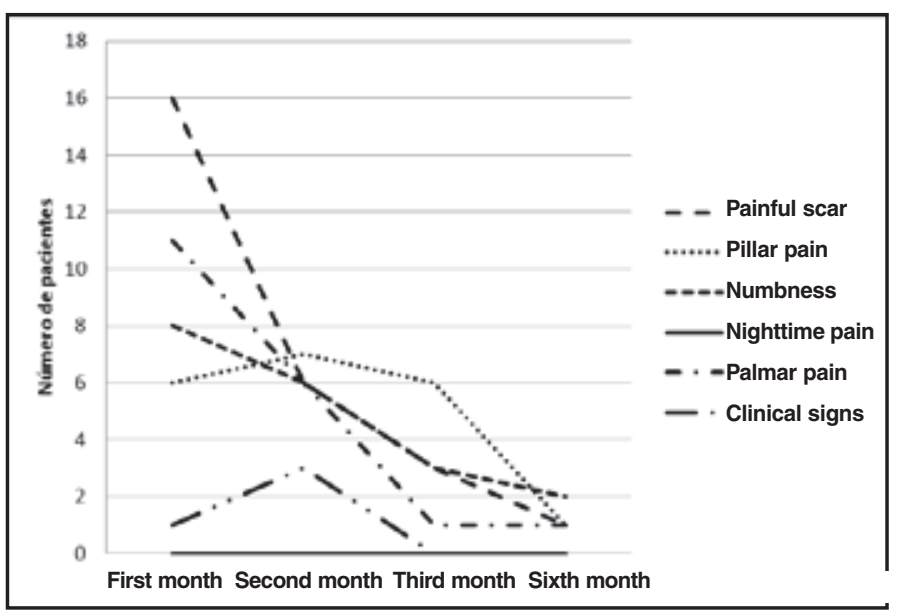

Figure 3 - Evolution of complaints of group 2.

\section{DISCUSSION}

Carpal tunnel syndrome is a frequent disease at orthopedic and hand surgery outpatient clinics, with high prevalence in the general population. It is the most common and most extensively studied compressive neuropathy in humans. Failures in conservative treatment lead to a large number of patients submitted to surgery.

The experimental model presented in this trial was established to propose a method that accelerates the functional recovery of patients submitted to surgery for the treatment of carpal tunnel syndrome, testing its efficacy. The search in medical literature did not produce any trial that could test the efficacy of lowlevel laser therapy in the postoperative state of carpal tunnel syndrome; therefore, the unprecedented nature of this study hinders the comparison of our results.

There are several studies that evaluate the postoperative results of release of the flexor retinaculum of the wrist for the treatment of carpal tunnel syndrome, 
with high rates of satisfactory results ${ }^{(1,2,7,17)}$. Our sample coincides with literature in terms of the predominance of female patients, mean age, preoperative symptoms and diversity of postoperative complaints.

The analysis of results evidences that patients treated with adjuvant laser therapy in the postoperative stage had fewer complaints in this period.

Literature lists a painful scar as the main complaint of operated patients. This also occurred in our study; however, in the first month, $31.03 \%$ of the patients from group 1 had such a complaint, against 55.17\% from group 2. In the following months, references to the painful scar symptom were constantly less common in group 1 than in group 2.

Pillar pain is also frequently associated with surgical failure, and it was present in our patients' complaints, yet progressively decreased during postoperative follow-up, and was nonexistent in group 1 after the sixth month.

Numbness (paresthesia) was also a frequent complaint, with incidence in $18.96 \%$ of the individuals in the first month, but in the second month none of them noticed such a symptom.

Nighttime pain was not experienced by any of the patients from either one of the groups in the postoperative period.

Pain in the palmar region was experienced by $32.76 \%$ of the patients in the first month, and to a lesser extent in those submitted to phototherapy.

The clinical signs of the disease were still present in $10.34 \%$ of the patients from group 1 in the first month and ceased in the following evaluations.

The neurofunctional evaluations demonstrated better results in the patients submitted to LLLT.

The various studies demonstrating the results of LLLT in neuronal regeneration and in the conservative

\section{REFERENCES}

1. Phalen GS. The carpal-tunnel syndrome. Seventeen years' experience in diagnosis and treatment of six hundred fifty-four hands. J Bone Joint Surg Am. 1966;48(2):211-28.

2. Howard RF. Hand and microsurgery. In: Miller M, editors. Review of orthopaedics. Philadelphia: Saunders; 2004. p. 308-312.

3. Pardini Júnior A, Freitas A, Tavares K. Antebraço, punho e mão. In: Hebert S, Barros Filho T, Xavier R, Pardini Júnior A, editores. Ortopedia e traumatologia princípios e prática. Porto Alegre: Editora Artmed; 2009. p. 231-253.

4. Seror P. Sonography and electrodiagnosis in carpal tunnel syndrome diagnosis, an analysis of the literature. Eur J Radiol. 2008;67(1):146-52.

5. Heybeli N, Kutluhan S, Demirci S, Kerman M, Mumcu EF. Assessment of outcome of carpal tunnel syndrome: a comparison of electrophysiological findings and a self-administered Boston questionnaire. J Hand Surg Br. 2002;27(3):259-64.

6. Cranford CS, Ho JY, Kalainov DM, Hartigan BJ. Carpal tunnel syndrome. J Am Acad Orthop Surg. 2007;15(9):537-48

7. Henrique A. Avaliação pós-operatória de 237 liberações cirúrgicas abertas para o tratamento de síndrome do túnel do carpo. Rev Bras Ortop. 2003;38(7):381-90.

8. Chang WD, Wu JH, Jiang JA, Yeh CY, Tsai CT. Carpal tunnel syndrome treated with a diode laser: a controlled treatment of the transverse carpal ligament. Photomed Laser Surg. 2008;26(6):551-7.

9. Yagci I, Elmas O, Akcan E, Ustun I, Gunduz OH, Guven Z. Comparison of splint- treatment of CTS led us to believe that laser therapy could be useful in the functional recovery process of the median nerve and could alleviate the symptoms perceived after the surgical procedure. Although it is an intuitive process at first, we sought an analytical method to test the hypothesis.

The study design was aimed at controlling treatment with the placebo and there was randomization to distribute the participants. We did not achieve the necessary structure to exclude the surgeon's awareness of the group to which the patients belonged. But we believe that the fact that only the evaluator knew whether the patients were being treated with laser or placebo led to slight distortion of results, since the evaluated complaints originated from the patients and not from subjective evaluations by the examiner. The electroneuromyographies were executed by examiners who did not come into contact with the study data, and thus produced objective results.

\section{CONCLUSIONS}

We consider this an initial study on the adjuvant therapeutic approach using low-level laser therapy in the postoperative period of carpal tunnel syndrome. Other studies will be necessary to validate the technique.

We concluded that the methodology presented was sufficient for the postoperative evaluation of the patients from the study.

The patients submitted to low-level laser therapy after surgical release of the flexor retinaculum in the wrist benefited from the treatment and obtained better functional results than those from the control group.

The technique was effective and without adverse effects among our patients.

ing and splinting plus low-level laser therapy in idiopathic carpal tunnel syndrome. Clin Rheumatol. 2009;28(9):1059-65.

10. Irvine J, Chong SL, Amirjani N, Chan KM. Double-blind randomized controlled trial of low-level laser therapy in carpal tunnel syndrome. Muscle Nerve. 2004;30(2):182-7.

11. Bakhtiary $\mathrm{AH}$, Rashidy-Pour A. Ultrasound and laser therapy in the treatment of carpal tunnel syndrome. Aust J Physiother. 2004;50(3):147-51.

12. Elwakil TF, Elazzazi A, Shokeir H. Treatment of carpal tunnel syndrome by lowlevel laser versus open carpal tunnel release. Lasers Med Sci. 2007;22(4):265-70.

13. Rochkind S, El-Ani D, Nevo Z, Shahar A. Increase of neuronal sprouting and migration using $780 \mathrm{~nm}$ laser phototherapy as procedure for cell therapy. Lasers Surg Med. 2009;41(4):277-81.

14. Gigo-Benato D, Geuna S, Rochkind S. Phototherapy for enhancing peripheral nerve repair: a review of the literature. Muscle Nerve. 2005;31(6):694-701.

15. Rochkind S, Geuna S, Shainberg A. Phototherapy in peripheral nerve injury: effects on muscle preservation and nerve regeneration. Int Rev Neurobiol. 2009;87:445-64.

16. Endo C, Barbieri CH, Mazzer N, Fasan VS. A Laserterapia de baixa intensidade acelera a regeneração de nervos periféricos. Acta Ortop Bras. 2008;16(5):305-310.

17. Alves MPT. Estudo prospectivo comparativo entre a descompressão do canal do carpo pela mini-incisão transversa proximal e a incisão palmar longitudinal convencional. Rev Bras Ortop. 2010; 45(5):437-444. 